\title{
Da teoria do rizoma à coexistência: uma aplicação projetual
}

\author{
The Concept of the Rhizome to coexistence: a projetual application
}

\author{
> Camila Ferreira Guimarães \\ Instituto de Arquitetura e Urbanismo \\ Universidade de São Paulo, Brasil \\ Universidade de Uberaba, Brasil \\ camilafguimaraes@usp.br
}

\begin{abstract}
From the concept of rhizome, developed by philosophers Gilles Deleuze and Félix Guattari, the article presented here seeks to establish a relation between the development of a conceptual architectural project, with bases in the formulations of the Rhizome, in order to enable coexistence within an urban network. Considering for the effective of the theory, the technology in the construction of media and networks. For that, is made a reading of a project developed as Final Work Undergraduate Architecture and Urbanism of the University of Uberaba in 2011.
\end{abstract}

Keywords: Rhizome; Coexistence; Networks.

\section{Introdução}

$\mathrm{O}$ artigo aqui apresentado busca relacionar a Teoria do Rizoma de Gilles Deleuze e Félix Guattari com a construção de um modelo projetual teórico passível de aplicação em projetos de arquitetura e urbanismo. Introduzindo de forma conceitual os seis princípios que permeiam a teoria do rizoma usados pelos autores citados com a intensão de possibilitar situações que permitam a coexistência. Assim, podemos pensar a construção desde um edifício no contexto da cidade à uma lógica espacial de uma rede de prédios e espaços públicos onde possam ocorrer a existência simultânea de diferentes pessoas, convivendo umas com as outras, trocando e compartilhando experiências cotidianas.

A atual configuração das cidades brasileiras que é baseada em um modelo exclusivo e segregativo das lógicas espaciais, tendo como resultado a diminuição, cada vez mais acentuada, da pluralidade dentro dos espaços públicos do ambiente urbano. Considerando esse panorama, tem-se a urgente necessidade de repensar o significado dos espaços e das suas possíveis interaçóes. A intenção de usar a Teoria do Rizoma para articular e abrir possibilidades de reverter essa situação é fundamentada na exposição e aplicação dos princípios da teoria elaborados por Deleuze e Guattari. Os seis princípios da Teoria do Rizoma foram definidos como: princípios de conexão, heterogeneidade, multiplicidade, ruptura a-significante, cartografia e decalconomia (Deleuze; Guattari, 1995). A partir dessa formulação pode-se entender, dentre muitos significados e interpretaçóes possíveis, que em um sistema rizomático todos os pontos podem ser conectados a outros, independente da sua natureza, e esse sistema pode ser rompido em qualquer parte, sofrendo construçóes e mutaçóes constantemente, ilustrando processos de territorialização, desterritorialização e reterritorialização (Deleuze; Guattari, 1995).

Isso nos faz refletir sobre a possibilidade de pensar a cidade e o edifício dessa maneira, fazendo uma livre interpretação dessa teoria aplicada na arquitetura e no urbanismo, encaro essa conceituaçáo dos autores citados como uma possibilidade de projetar pensando nas relaçóes entre os habitantes de determinado local. Sendo assim, um projeto pensado para uma diversidade ilimitada de pessoas. Projetos que elaborados em conjuntos passam a constituir um sistema de redes. Como uma possibilidade da aplicação da teoria é usado como exemplo um projeto conceitual de um edifício para diferentes pessoas, que em algum momento de suas vidas possam estar desabrigadas, ou seja temporariamente sem um local fixo e definido para realizar suas atividades cotidianas. $O$ projeto escolhido foi elaborado em um Trabalho Final de Graduação no ano de 20111 (figura 1) sob a orientação da professora Dra Varlete Aparecida Benevente. Além de permitir a coexistência, esse modelo conceitual usado como exemplo, ainda aborda a questóes de adaptabilidade e mutação, permitindo que o projeto seja sempre uma edificação em constante processo de construção.

Assumindo a ideologia de uma possível aplicação da teoria, esse artigo abre um espaço para pensarmos como podemos articular e

1 Projeto desenvolvido como Trabalho Final de Graduação do curso de Arquitetura e Urbanismo da Universidade de Uberaba, no ano de 2011, sob a orientaçáo da professora Dra. Varlete Aparecida Benevenete. 
rearticular as mudanças da contemporaneidade com um ambiente urbano inclusivo e múltiplo. Diante da riqueza teórica de Teoria do Rizoma, esse artigo tem o papel de resgatar sua utilização e mostrar a amplitude de sua aplicação em diversas áreas do conhecimento.

"Não chegar ao ponto em que não se diz mais EU, mas ao ponto em que já não tem qualquer importância dizer ou não dizer EU. Não somos mais nós mesmos. Cada um reconhecerá os seus. Fomos ajustados, aspirados, multiplicados." (Deleuze; Guattari, 1995, p. 17)

\section{Deleuze e Guatarri: o conceito de rizoma}

O conceito de Rizoma desenvolvido pelos filósofos Deleuze e Guattari, segundo Ferreira (2008), faz uma reflexão a respeito do conceito das redes, o rizoma seria a expressão da multiplicidade, que por meio de diversas ligaçóes pode transformar constantemente em novas formas. Sendo justamente por essa multiplicidade que a teoria foi escolhida para embasar este artigo. Assim, diante de toda a complexidade do mundo contemporâneo podemos encontrar bases que possibilitam o desenho urbano e arquitetônico voltado para todos os habitantes e, ao mesmo tempo, considerando todas as variáveis que levam as diferenças.

No livro Mil Platôs, os autores, segundo Ferreira (2008), criaram um conceito com base em um sistema composto por multiplicidades, o rizoma, contrastando com o sistema arborescente, onde há um tronco principal que guia todos os outros conceitos. No sistema rizomático (figura 2), não existe esse elemento principal, os elementos são ao mesmo tempo únicos e múltiplos, Deleuze (1980) chama essa lógica de raiz fasciculada, a base para a Teoria do Rizoma. Importante destacar as inúmeras possibilidades que podem resultar de um sistema construído dentro desse conceito.

Figura 1: Projeto desenvolvido como Trabalho Final de Graduação do curso de Arquitetura e Urbanismo da Universidade de Uberaba - Aplicação do conceito de Rizoma.
Para uma melhor definição do que seria essa teoria, Deleuze e Guattari estipularam seis princípios norteadores, são eles: $1^{\circ}$ e $2^{\circ}$ : Princípios de conexão e heterogeneidade, que abordam a possibilidade da conexão de todos os pontos do rizoma; $3^{\circ}$ : Princípio da multiplicidade; $4^{\circ}$ : Princípio de ruptura a-significante, definindo a liberdade que o rizoma tem de se romper em qualquer um dos seus pontos, assim como poder retomar o seu processo; $5^{\circ}$ e $6^{\circ}$ : Princípio de cartografia e decalconomia, onde o rizoma é considerado um modelo transformacional e subjetivo, podendo gerar inúmeros decalques com infinitas reproduçôes. (Deleuze; Guatarri, 1995)

Usando esses princípios da Teoria do Rizoma, podemos projetar espaços que definidos dentro de uma lógica de rede e em constante interação possam propiciar a coexistência entre as pessoas que compóem o ambiente urbano.

\section{Coexistir e redes}

Assim, usando a Teoria do Rizoma no campo da Arquitetura e do Urbanismo podemos criar redes de edifícios e espaços públicos,

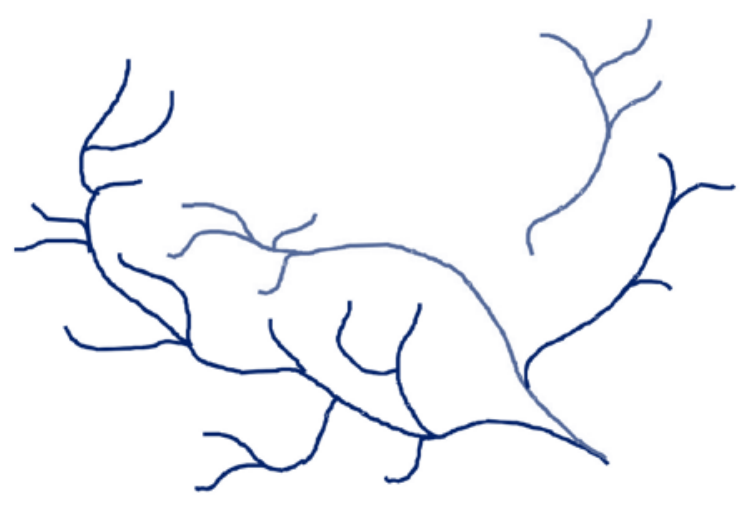

Figura 2: Modelo rizomático.

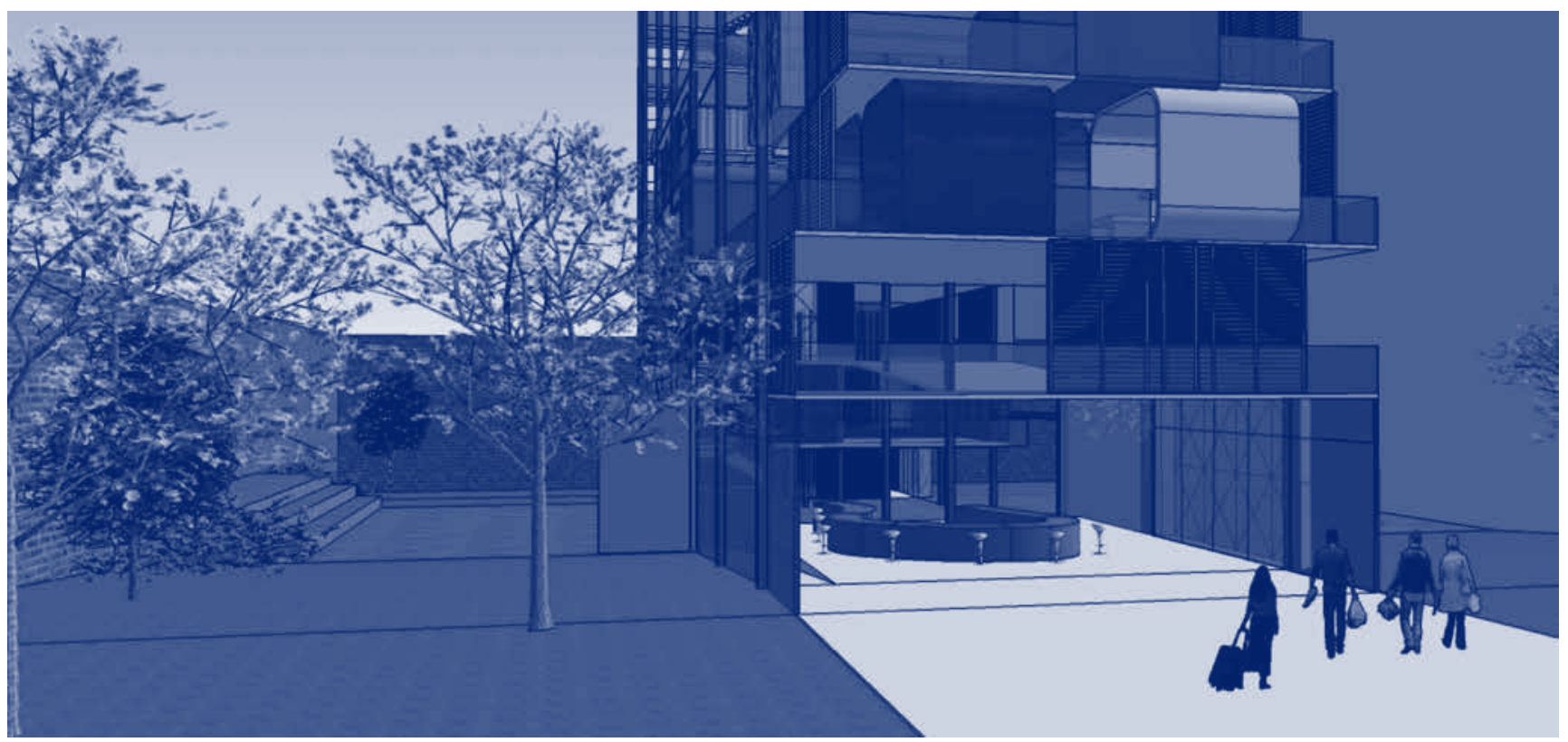


que por meio da tecnologia e da comunicaçáo podem propiciar o estimulo à coexistência. Essas redes seriam possíveis por meio da conexão entre os espaços, de forma que o todo constitua uma unidade, considerando todas suas multiplicidades.

As criaçóes de redes virtuais, que se estabeleceriam por meio da comunicação através de sistemas tecnológicos, também estariam ligadas ao processo de reterritorialização das pessoas, que por meio do contato com os seus locais de origens, poderiam criar a sensação de reterritorialização virtual. "(...) e há processos que devemos chamar de desterritorialização, o modo como saímos do território.” (Deleuze, 1989, p. 20)

Um importante ponto destacado no conceito de Rizoma é a possibilidade da multiplicidade, da convivência de diferentes pessoas em um mesmo local, o que nos leva ao conceito de coexistência, afim de diminuir os conflitos gerados pelo o que possa ser desconhecido.

Esses conflitos aumentados pelas desigualdades sociais, fazem com que as pessoas não tolerem conviver com o que é considerado diferente dos seus padróes pré-estabelecidos, chamando atençáo para a necessidade de criar espaços que estimulem a coexistência de diferentes grupos e que proporcionem às pessoas novas experiências, aceitando e evidenciando a multiplicidade da cidade contemporânea.

“Coexistência é uma noção que está se consolidando sobre novas bases, associada à existência simultânea de opostos e, ainda, relacionada prioritariamente a situaçóes de conflitos, sejam eles, étnicos, religiosos, políticos, ideológicos, culturais, de classe, de identidades, de gênero, entre outros". (Santos, 2011)

\section{Aplicação projetual}

Com base na exploração dos conceitos de Rizoma, coexistência e rede foi desenvolvido um projeto como Trabalho Final do curso de graduação em Arquitetura e Urbanismo (figura 3). Esse projeto segue os conceitos propostos pelos filósofos Deleuze e Guattari, na Teoria do Rizoma, publicada em 1980 na obra Mil Platôs, fragmentada em cinco volumes.

Nessa proposta projetual de um edifício destinado às pessoas sem um local definido para morar, independente do motivo que

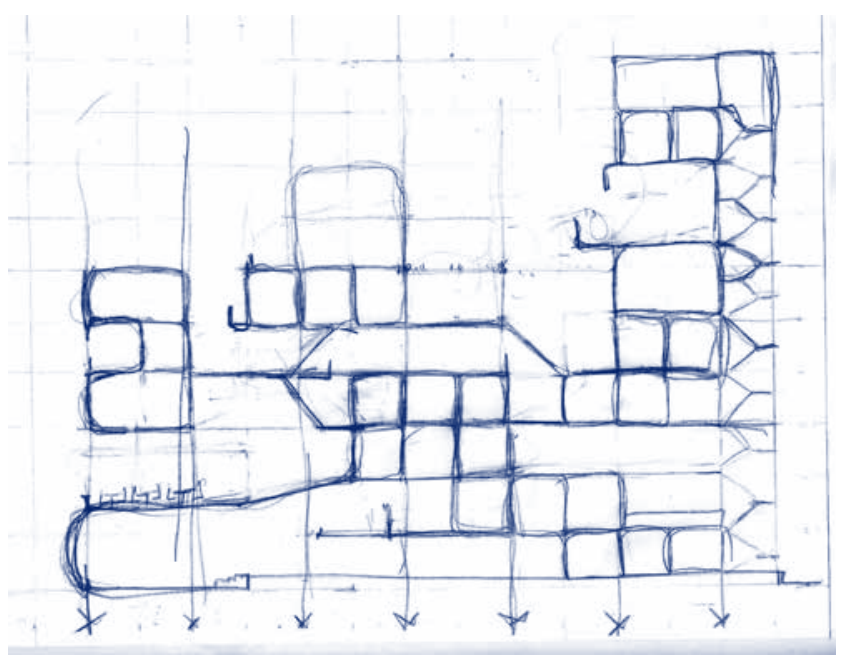

Figura 3 : Croqui do projeto. as levaram a essa situação. Os seis princípios da Teoria do Rizoma foram usados da seguinte maneira:

- Conexão: no rizoma há sempre possibilidade de conectar partes - Aplicação no projeto: fazer com que as unidades habitacionais possam ser conectadas criando interaçóes dentro do edifício;

- Heterogeneidade: possiblidade de conectar diferentes naturezas - Aplicação no projeto: junção de elementos distintos (unidades habitacionais, espaços públicos, entre outros) formando um organismo;

- Multiplicidade: Aplicação no projeto: está representada desde as diferenças dos usuários aos elementos empregados na constituição física do edifício e nos múltiplos usos que são possíveis das partes constituintes do edifício;

- Ruptura a-significante: Relacionada aos processos de territorialização, desterritorialização e reterritorialização - Aplicação no projeto: os processos pelos quais as pessoas que vẫo utilizar esse abrigo passam, até chegar a reterritorialização provisória gerada por esse equipamento;

- Princípios de cartografia e decalconomia: corresponde aos múltiplos agenciamentos que configuram um mapa em constante mudança. Aplicação no projeto: possiblidades de mudança da configuraçáo interna do projeto em consequência das mudanças comportamentais. E a ligação desse projeto com outras construçóes na cidade por meio de uma rede de construçôes, ou até mesmo, uma rede virtual de comunicação.

A proposta projetual tenta trazer essas ideias desenvolvidas por esses filósofos. Assim, podemos perceber que a teoria desenvolvida nos anos 1980, possuí um conteúdo completamente adequado para as questóes contemporâneas, não apenas da arquitetura, mas de diversos segmentos.

A definição de um objeto como resultado pode constituir um paradoxo, pois esse conceito filosófico engloba questóes que vão além de objetos definidos, portanto a proposta projetual se apresenta em forma de estudos e diagramas sugerindo um edifício composto por unidades que permitam diversas alteraçóes.

O projeto se enquadra dentro do processo de reterritorialização provisória, visto que o local abrigará esses indivíduos por um tempo determinado, ocorre também a reterritorialização por meio de funçôes que esse equipamento pode possuir, como unidades informatizadas, que visam uma reterritorialização virtual.

Como foi discutido ao longo desse trabalho, o projeto consiste em um edifício composto por cápsulas que tem a função de acomodar pessoas desabrigadas, fornecendo os itens básicos cotidianos de uma casa como local para descanso, higiene, comer e além desses itens, esse edifício terá também, locais de recreação, de assistência médica, de informação, de educação.

Seguindo o conceito do Rizoma, que considera o tempo como um fator determinante, onde nada é o que é por muito tempo, tudo está em constante transformação, o programa desse edifício é pensado dessa maneira. Elaborou-se um programa básico, que pode ser modificado a qualquer momento, já que pensamos em uma rede de unidades de abrigos e de moradores que usam provisoriamente 
os espaços, aumentando ainda mais a instabilidade de um programa com números definidos de cômodos e usos específicos.

O resultado final desse edifício (figura 4) será um mapa, um decalque instantâneo de uma situação momentânea, a estrutura e a concepçáo do prédio permitirá que ocorra essas mudanças.

Além desse conceito, o projeto propóe não o habitar, mas o co-habitar. Segundo Tiburi (2011), quando falamos em habitar nos referimos ao que é conhecido e, de certa forma, negamos o que não nos é habitual, portanto esse equipamento carrega a função de permitir o que não habitual, onde as diferenças convivem. A proposta projetual cria locais onde mesmo as pessoas que não moram ali possam interagir com os moradores, permite que tenha a multiplicidade da cidade em um edifício

\section{Considerações Finais}

A riqueza de aplicaçôes da Teoria do Rizoma de Deleuze e Guattari na Arquitetura e no Urbanismo foi evidenciada nesse trabalho na sua aplicação em uma proposta projetual.

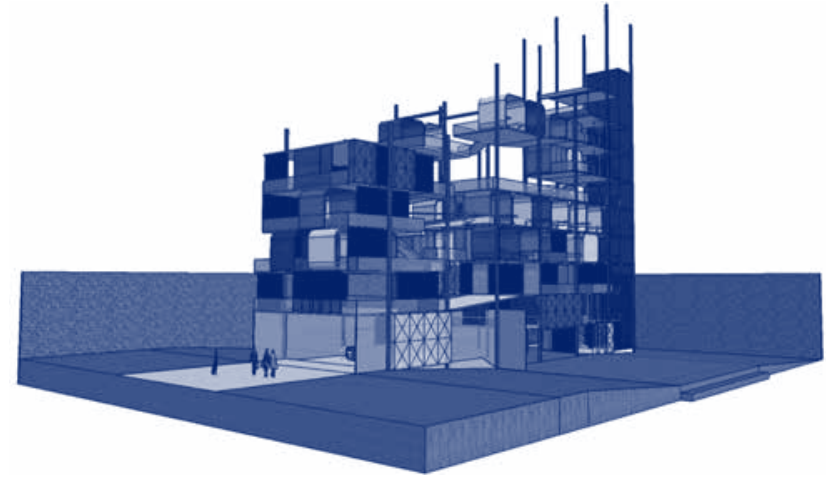

Figura 4: Uma das possíveis configuraçôes do projeto com base no conceito de Rizoma
Pensar nas questóes da arquitetura e da sociedade contemporâneas foi a essência para chegar no conceito principal que embasa o projeto: a coexistência, a arquitetura como meio de promover a convivência de diferentes pessoas. Esse conceito que fez parte das premissas projetuais foi aliado a Teoria do Rizoma de Deleuze e Guattari e aplicados no projeto, fazendo com que este se enquadre dentro das necessidades do abrigo, que se alteram com o tempo.

\section{Agradecimentos}

Agradeço à professora Dra. Varlete Aparecida Benevente da Universidade de Uberaba pela orientaçáo no projeto analisado nesse trabalho e pela introdução ao conhecimento e compreensão do conceito de Rizoma de Deleuze e Guattari.

\section{Referências}

Deleuze, G., Guattari, F. Mil Platôs - Capitalismo e Esquizofrenia. Ed. 34. Rio de Janeiro, 1997.

Deleuze, G., Parnet, C. Abecedário de Gilles Deleuze. Éditions Montparnasse, Paris. Filmado em 1988-1989. Publicado em: 1995 .

Ferreira, F. T. Rizoma: um método para as redes? In: Liinc em Revista, v.4, n.1, março 2008, Rio de Janeiro, p.28-40.

SANTOS, D. M. Coexistência: notas para um projeto de pesquisa. In:V!RUS, São Carlos, n. 4, dez. 2010. Disponível em: <http:// www.nomads.usp.br/virus/virus04/?sec=6\&item=1\&lang=pt $>$. Acesso em: 2014.

Tiburi, M. Habitar como espaço das diferenças. V!RUS, São Carlos, n. 5, jun. 2011. Disponível em: <http://www. nomads.usp.br/virus/virus05/?sec $=5$ \&item $=2$ \&lang $=\mathrm{pt}>$. Acesso em: 2014. 